\title{
Evaluation of Improved Tef [Eragrostisteff /Zucc./Trotter] Production Technologies in Central High Lands of Ethiopia
}

\author{
Bekele Gemechu*, Amha Besufekad
}

College of Development Studies, Addis Ababa University, ETHIOPIA

${ }^{*}$ Corresponding Contact:

Email: oliyad.hn2@gmail.com

\begin{abstract}
A study was carried out to evaluate the performance of improved varieties of tef and production technologies in Becho district of Oromia, Centeral Ethiopia. Five improved tef varieties along with the local were selected and used as treatments (that is, Dega tef (T1), Guduru (T2), Kena (T3), Kora(T4),Quncho(T5) and Local (T6)) arranged in a Randomized Complete Block Design (RCBD) with six replications using six farmers' fields. Yield and yield related parameters were analyzed using SAS statistical software version 9.0. Economic analysis/profitability, preference/acceptability, gender and nutrition and environmental suitability data recording were performed to compare treatments advantages and identify the best performing varietity/ies. All the yield and yield related components were significantly different between the varieties at $5 \%$ probability level \%) except for plant height in which there was no significant difference among varieties. Variety Dega tef gave the highest grain yield with average grain yield of $3610.6 \mathrm{~kg} / \mathrm{ha}$ followed by Quncho and Kora and also had about $40 \%$ yield advantage over the local variety with average grain yield of $2577.83 \mathrm{~kg} / \mathrm{ha}$ and had about $116.95 \%, 110.25 \%$ and $90.80 \%$ yield advantage over the national, regional and zonal average yield of tef in 2016/2017 Meher season of CSA data respectively. Based on farmer's preference analysis variety Dega tef had high acceptability $(75 \%)$ followed by Quncho ( $73 \%)$ and Kora (70\%). Guduru variety has the least in acceptability $(21 \%)$. As the result from the economic analysis showed that Dega tef variety had the maximum net benefit $(79,536.69 \mathrm{bir} / \mathrm{ha})$ followed by Quncho $(67,106.97 \mathrm{birr} / \mathrm{ha})$ and Kora $(63,746.96 \mathrm{birr} / \mathrm{ha})$. Variety Guduru had the least net benefit result of about $53,648.17 \mathrm{birr} / \mathrm{ha}$. Based on the rules of decision making and the integrated scoring set for technology validation, two of the three improved varieties meet the requirements to be recommended. Therefore, we recommend Dega tef, Quncho, and Kora varieties for Becho areas and other areas with similar agro-ecological conditions in the central highlands of Ethiopia.
\end{abstract}

Key words:

Becho, economic analysis, environmental suitability, farmers' acceptability, gender aspect, integrated validation, protocol 


\section{INTRODUCTION}

Tef [Eragrostis tef (Zucc.) Trotter] is the major food crop in Ethiopia where it is annually cultivated on more than three million hectares of land (CSA 2017). Annually it accounts for about $24 \%$ of the total acreage and $17.29 \%$ of the gross grain production of the major cereals cultivated in the country (CSA 2017). The crop species has its centres of both origin and diversity in Ethiopia (Vavilov 1951). Compared to other cereals, tef is more tolerant to extreme environmental conditions especially to water-logging. It is unique in its ability to grow and yield on poorly drained Vertisols which most cereals cannot tolerate. Unlike other cereals, the seeds of tef can be easily stored under local storage conditions without losing viability since the grains are resistant to attack by storage pests (Ketema, 1997). Tef grain is also a rich source of protein and nutrients and has additional health benefits including that the seeds are free from gluten (Spaenij-Dekking et al., 2005). According to a recent study, the bio-available iron content was significantly higher in tef bread than in wheat bread (Alaunyte et al., 2012). In general, tef provides quality food and grows under marginal conditions, many of which are poorly suited to other cereals. However, tef is considered to be an orphan crop since it is only of regional importance and has until recently not been the focus of crop improvement (Naylor et al., 2004; Assefa, 2014).

Teff cultivation as a cereal food grain restricted to Ethiopia, except in very small quantities in Eritrea and recently, in the USA, the Netherlands, and Israel. Teff is also gaining popularity as health food (Spaenij-Dekking et al., 2005). However, the plant is known elsewhere in the world such as in South Africa, India, Pakistan, Uganda, Kenya, and Mozambique mainly as a forage or pasture crop.

In Ethiopia, tef grain is mainly used for food after baking the ground flour into pancake-like soft and sour bread, injera, which forms the major component of the favourite national dish of most Ethiopians. It is also consumed in the form of porridge, and slightly fermented or un-fermented non-raised bread (kita and anebabero). Although recent economic feasibilities might have limited such uses, the grain is also used for brewing native beer, talla, and more alcoholic cottage liquor, katikalla or arakie.

The long-sustained extensive cultivation of tef in Ethiopia can be attributed to its relative merits over other cereals both in husbandry and utilization (Ketema, 1993). Of these, its merits in cultivation, include: (a) versatile adaptation 0 - $3000 \mathrm{~m}$ above sea level; (b) resilience to both drought and waterlogging stresses; (c) fitness for various cropping systems; (d) use as a catch and low-risk reliable crop especially in replacement cultures for failures of early sown long-season crops (e.g. maize and sorghum) due to environmental calamities or pests; and (e) little or no serious threats of disease and pest epidemics, at least, in its major production belts. On the other hand, its beneficial features with respect to utilization involve: (1) best quality and most consumer-preferred injera of the grains; (2) high returns in flour (Ebba 1969) and in injera; (3) minimal post-harvest losses due to storage pests and diseases coupled with high storage longevity (storability); (4) importance of the straw mainly as fodder for cattle and as a binder of mud used for plastering walls of local houses; and (5) cash crop value owing to the high market prices of both the grains and the straw.

Out of the total grain crop area, $81.27 \%(10,219,443.46)$ hectares) was under cereals. Tef, maize, sorghum and wheat took up $24.00 \%$ (about 3,017,914.36 hectares), $16.98 \%$ (about $2,135,571.85$ hectares), $14.97 \%(1,881,970.73$ hectares $)$ and $13.49 \%(1,696,082.59$ hectares $)$ of the grain crop area, respectively. As to production, the tables paint similar picture as that of 
the area. Cereals contributed $87.42 \%$ (about 253,847,239.63 quintals) of the grain production. Maize, tef, wheat and sorghum made up $27.02 \%$ (78,471,746.57 quintals), $17.29 \%$ (50,204,400.47 quintals), $15.63 \%$ (45,378,523.39 quintals) and $16.36 \%(47,520,956.04$ quintals $)$ of the grain production respectively (CSA 2017).

Despite its popularity as a food crop, its productivity is very low (national average of about 1.6 tons/ha) (CSA 2017) mainly due to difficulties in its management and low genetic potential of local varieties as well as low adaptation of the improved varieties to different agro ecologies of the areas. Thus, this work is mainly incited to validate/evaluate the performance of the improved varieties of tef in central high lands which were released from the research systems of the country with the following objectives.

\section{Objectives}

- To evaluate and identify the best performing teff varieties and production technologies in central high lands of Ethiopia.

- To generate evidence on improved tef varieties and production technologies.

\section{MATERIALS AND Methods}

\section{Description of the study area}

The study area (Bacho district) is located in mid agro-ecology of South west Shewa zone of Oromia Regional State at $8^{0} 35^{\prime} 0^{\prime \prime} \mathrm{N}$ latitude and $38^{\circ} 15^{\prime} 0^{\prime \prime} \mathrm{E}$ longitude; about $80 \mathrm{~km}$ South west of Addis Ababa. It has an altitude range of 2,106 to 2,600 masl with mean annual temperatures ranging from $16{ }^{\circ} \mathrm{C}$ to $25{ }^{\circ} \mathrm{C}$. The long term weather information revealed that the area has unimodal rainfall pattern in which the effective rainy season/main rainy season is from May to September with the mean annual rainfall of about 1,300 millimeters per year. In term of soil, the study area is characterized by deep black vertisol which is moderately fertile and suitable for the production of crops such as tef, wheat, chick pea lentil and other horticultural crops and forages.

\section{Varietal/treatment selection}

For the evaluation activity the selection of the varieties was based on the suitability to the area and the varieties should be newly released and new to the area. The varieties used for the evaluation activities were identified and obtained from the relevant research system of the country. The varieties were considered as treatments and the participant farmers were as block/replications arranged in randomize complete block design (RCBD).

\section{Site selection and land preparation}

Site selection is important for the successful implementation of the activity. The preceding crop should be physiologically dissimilar crop in order to minimize the problem of nutrient imbalance and pest build up. 4 - to 5 times plowing is required depending on the type of soil texture. Pre plowing helps for the decomposition of any debris in the field. The next round plowing should be carried out when the first rain begins before it comes to the saturation point. This helps to facilitate the decomposition of crop residues and avoid weed remnants. The following plowings are important to prepare the field to its finest level so that the well prepared can facilitate uniform germination and good field establishment of the crop.

\section{Seed rate and planting methods}

Land preparation was accomplished by plowing 4-5 times using local "Maresha". This helps to make the soil particles fine. Planting was carried out with broad casting method since 
there was no appropriate raw planter that can properly handle raw planting of tef on the heavy vertisol of the area which is a beat difficult for raw making at tef planting time. Tef planting in the area is commonly practiced from July to early August and for this trial planting was conducted on mid- July. A seed rate of $30 \mathrm{~kg} /$ ha was used for all tef varieties under evaluation.

\section{Fertilizer application}

Even though the use of chemical fertilizers varies based on the soil conditions and crop types, fertilizer application based on area specific fertilizer recommendation is important to exploit the maximum potential of the area. For this specific trial, $100 \mathrm{~kg} / \mathrm{ha}$ NPS and 50 $\mathrm{kg} / \mathrm{ha}$ Urea at planting and $50 \mathrm{~kg} / \mathrm{ha}$ Urea (35-40) days after planting was used with broadcasting method of application.

\section{Data collection and Analysis}

Evaluation of tef varieties (Dega tef, Guduru, Kena, Kora, Quncho and Local was conducted on 6 selected farmers' field on $100 \mathrm{~m}^{2}$ of land per household for each variety. Data collection was based on the protocol developed by the Wageningen University and Research and CASCAPE researchers. Based on this protocol agronomic data like days to flowering, and days to maturity, plant height, disease and pest score, grain yield, and biomass yield were collected from the selected plots. Economic data and farmers' preference, environmental sustainability, nutrition and gender aspect were also part of the collected data. After collecting the necessary data, analysis and interpretation was executed with the use of SAS software in order to develop a clear and precise report of the activity. After analyzing the collected data of each parameter the result was scored on the scoring table and then displayed on the spider diagram.

\section{Result AND Discussion}

\section{Agronomic Performance of the Varieties}

For the performance evaluation of improved tef varieties in terms of their yield potential for the specific locality and similar Agro-ecologies, different parameters were recorded. All the yield and yield related parameters were significantly different between the varieties at $5 \%$ probability level. Dega tef was the high yielder followed by Quncho and Kora (Table 1).

Table 1: Agronomic parameters for tef field evaluation trial at Becho

\begin{tabular}{|c|c|c|c|c|c|c|c|}
\hline No & Treatments & $\begin{array}{c}\text { Grain Yield } \\
\text { in kg/ha }\end{array}$ & $\begin{array}{c}\text { Biomass Yield } \\
\text { in } \mathbf{~ k g / h a}\end{array}$ & $\begin{array}{c}\text { Flowering } \\
\text { date }\end{array}$ & $\begin{array}{c}\text { Maturity } \\
\text { date }\end{array}$ & $\begin{array}{c}\text { Plant } \\
\text { height }\end{array}$ & $\begin{array}{c}\text { Harvest } \\
\text { Index }\end{array}$ \\
\hline $\mathbf{1}$ & Dega tef & $3610.67 \mathrm{a}$ & $9765.8 \mathrm{a}$ & $59.83 \mathrm{c}$ & $103 \mathrm{c}$ & 0.99 & $0.37 \mathrm{a}$ \\
\hline $\mathbf{2}$ & Guduru & $2319.17 \mathrm{e}$ & $7789.5 \mathrm{c}$ & $64.66 \mathrm{~b}$ & $110 \mathrm{~b}$ & 1.04 & $0.30 \mathrm{~b}$ \\
\hline $\mathbf{3}$ & Kena & $2346.67 \mathrm{e}$ & $8163.5 \mathrm{c}$ & $55.83 \mathrm{~d}$ & $100 \mathrm{c}$ & 0.96 & $0.29 \mathrm{~b}$ \\
\hline $\mathbf{4}$ & Kora & $2874.17 \mathrm{c}$ & $8534 \mathrm{bc}$ & $69.66 \mathrm{a}$ & $111 \mathrm{~b}$ & 1.04 & $0.35 \mathrm{a}$ \\
\hline $\mathbf{5}$ & Quncho & $3139.17 \mathrm{~b}$ & $8035.8 \mathrm{c}$ & $66.66 \mathrm{~b}$ & $112.66 \mathrm{~b}$ & 0.98 & $0.39 \mathrm{a}$ \\
\hline $\mathbf{6}$ & Local & $2577.83 \mathrm{~d}$ & $9307.7 \mathrm{ab}$ & $71.66 \mathrm{a}$ & $119 \mathrm{a}$ & 0.99 & $0.27 \mathrm{~b}$ \\
\hline & Mean & 2811.27 & 8599.3 & 65 & 109 & 1.00 & 0.33 \\
\hline & CV \% & 4.16 & 8.76 & 3.08 & 2.96 & 8.24 & 11.2 \\
\hline & $\mathrm{P}$ & 0.001 & 0.001 & 0.001 & 0.001 & $\mathrm{Ns}$ & 0.01 \\
\hline
\end{tabular}

According to the result from the analysis of the six tef varieties under evaluation there was a significant difference $(5 \%)$ among the varieties for all agronomic parameters considered except 
for plant height in which there was no significant difference among varieties. Variety Dega tef gave the highest grain yield with average grain yield of $3610.6 \mathrm{~kg} / \mathrm{ha}$ followed by Quncho and Kora and also has about $40 \%$ yield advantage over the local variety with average grain yield of $2577.83 \mathrm{~kg} /$ ha which was supplemented by the study made by Teklu and Tefera 2005.
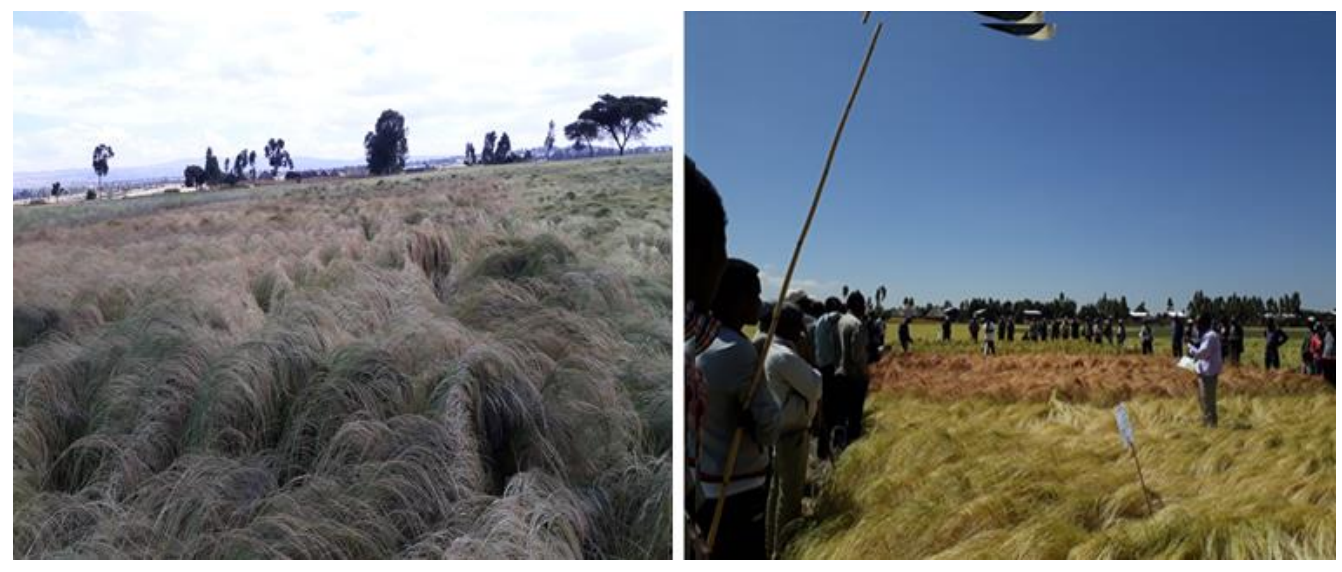

Fig 1: Field performance of tef validation trial at different stages

In addition, the yield of the selected cultivar Dega tef has a $116.95 \%, 110.25 \%$ and $90.80 \%$ yield advantage over the national, regional and zonal average yield of tef in 2016/2017 Meher season of CSA data respectively (CSA 2017). As observed from the average yield obtained from experimental site of all tef varieties under evaluation it is by far greater than the average yield recorded by the CSA 2017 for national average $(1664 \mathrm{~kg} / \mathrm{ha})$, regional average $(1717 \mathrm{~kg} / \mathrm{ha})$ and zonal average $(1892 \mathrm{~kg} / \mathrm{ha})$. Dega teff variety with an average grain yield of $3610.6 \mathrm{~kg} / \mathrm{ha}$ was identified and it surpasses the local variety $(2577.83 \mathrm{~kg} / \mathrm{ha})$ and the zonal yield (CSA, 2016/17) by about $40 \%$ and $90.80 \%$, respectively (Fig 2).

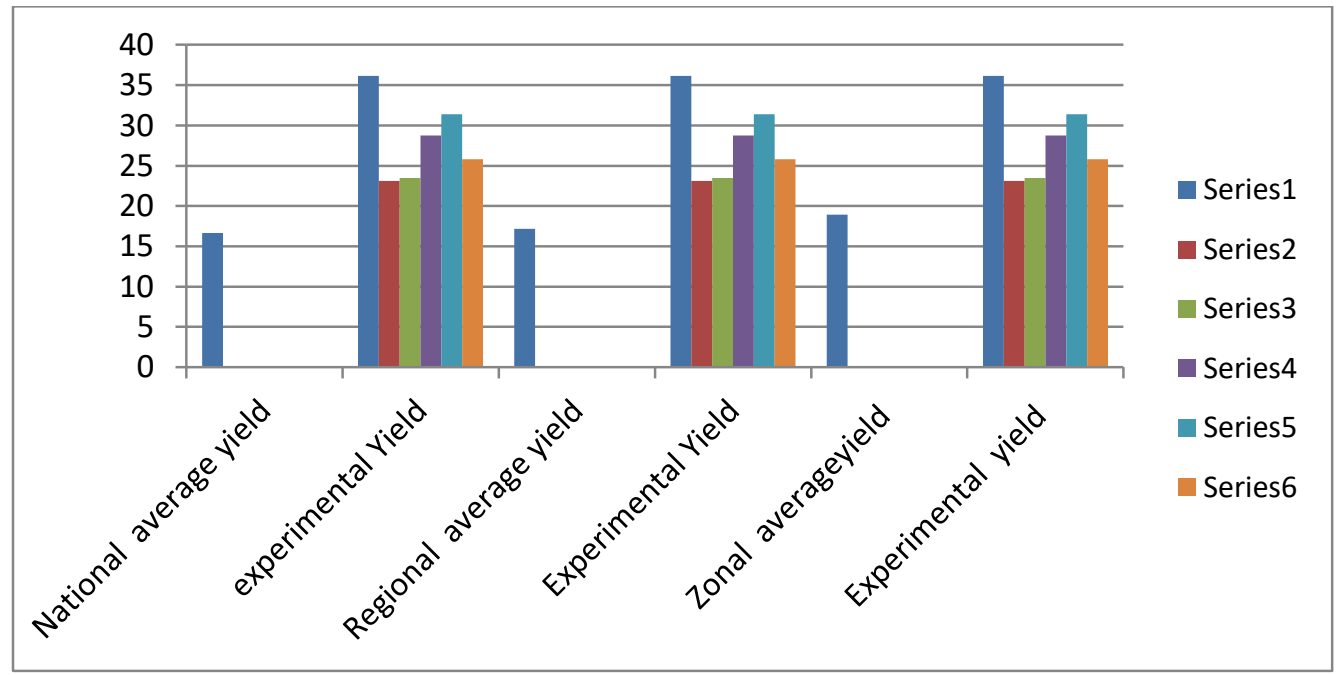

Fig 2: Experimental yield vs CSA data of 2017

The result obtained is in line with the study by(Tefera and Belay 2006), in which farmers using improved cultivars and management practices can obtain yields up $2500 \mathrm{kgha}^{1}$ while the yield potential under optimal management and when lodging is prevented, is as high 
as $4500 \mathrm{~kg} \mathrm{ha}^{1}$ (Teklu and Tefera 2005). The treatments/varieties were arranged as the series in the figure below as series1=Dega tef, series $2=$ Guduru, series3=Kena, series $4=$ Kora, series5= Quncho and series 6= Local.

\section{Profitability}

The statistical analysis of tef performance evaluation trial conducted at Becho Woreda indicated that there was a significant difference among the treatment yields. Since the analysis of variance showed significant yield difference between the treatments, we need to go further for the partial budget analysis. The economic analysis was conducted to identify the most profitable tef variety/practice from the six validated varieties based on the additional investment they require and the marginal benefit they generate to the farmer The marginal benefit for each cultivar was estimated according to the (CIMMYT 1988) procedure. To compensate for the possible inflated estimation of average grain yield, mostly because of the method of input application and the small plot effect, average grain yield of cultivars was adjusted downwards by $10 \%$ to calculate gross field benefits. The cost of seed is the only cost that was found to vary across treatments; therefore, the difference in average grain yield and the cost of seed are the only factors to influence marginal benefit.

Table 2: Profitability analysis for tef varieties

\begin{tabular}{|l|c|c|c|c|c|c|}
\hline & \multicolumn{7}{|c|}{ Varieties } \\
\hline Inconstant variables & Dega tef & Guduru & Kena & Kora & Quncho & Local \\
\hline Average grain yield (kg/ha) & 3610.67 & 2319.17 & 2346.67 & 2874.17 & 3139.17 & 2577.83 \\
\hline Adjusted grain yield (kg/ha) & 3249.60 & 2087.25 & 2112.00 & 2586.75 & 2825.25 & 2320.04 \\
\hline Average straw yield(kg/ha) & 6155.13 & 5470.33 & 5816.83 & 5659.82 & 4896.63 & 6729.87 \\
\hline Adjusted straw yield (kg/ha) & 5539.62 & 4923.3 & 5235.15 & 5093.84 & 4406.97 & 6056.89 \\
\hline Gross field benefits of grain (birr/ha) & $\mathbf{6 8 2 4 1 . 6}$ & $\mathbf{4 3 8 3 2 . 2 5}$ & $\mathbf{4 4 3 5 2}$ & $\mathbf{5 4 3 2 1 . 7 5}$ & $\mathbf{5 9 3 3 0 . 2 5}$ & $\mathbf{4 8 7 2 0 . 8 4}$ \\
\hline Gross field benefits of straw (birr/ha) & $13,295.09$ & $11,815.92$ & $12,564.36$ & $12,225.21$ & $10,576.72$ & $14,536.54$ \\
\hline Total Gross field benefits (\$/ha) & $\mathbf{8 1 , 5 3 6 . 6 9}$ & $\mathbf{5 5 , 6 4 8 . 1 7}$ & $\mathbf{5 6 9 1 6 . 3 6}$ & $\mathbf{6 6 5 4 6 . 9 6}$ & $\mathbf{6 9 , 9 0 6 . 9 7}$ & $\mathbf{6 3 2 5 7 . 3 8}$ \\
\hline Cost of seed (birr/ha) & 2000 & 2000 & 2000 & 2800 & 2800 & 1500 \\
\hline Total costs that vary (birr/ha) & 2000 & 2000 & 2000 & 2800 & 2800 & 1500 \\
\hline Net benefits (birr/ha) & $\mathbf{7 9 , 5 3 6 . 6 9}$ & $53,648.17$ & $54,916.36$ & $63,746.96$ & $67,106.97$ & $61,757.38$ \\
\hline Marginal profit & $\mathbf{3 9 7 6 . 8 3}$ & $\mathbf{2 6 8 2 . 4}$ & $\mathbf{2 7 4 5 . 8}$ & $\mathbf{2 2 7 6 . 6 7}$ & $\mathbf{2 3 9 6 . 6 7}$ & $\mathbf{4 1 1 7 . 1 5}$ \\
\hline
\end{tabular}

\section{Note}

- Average yield $(\mathrm{Kg} / \mathrm{ha})=$ average yield of a given variety over farmers' fields calculated as $\mathrm{kg} / \mathrm{ha}$.

- Adjusted yield $(\mathrm{Kg} / \mathrm{ha})=$ average yield adjusted downwards by $10 \%$ expressed as $\mathrm{kg} / \mathrm{ha}$.

- $\quad$ Gross field benefits $($ birr $/ \mathrm{ha})=$ Adjusted yield $(\mathrm{kg} / \mathrm{ha}) *$ field price of the crop (birr $/ \mathrm{kg})$

- Cost of seed (birr/ha) = Cost of seed for a given cultivar calculated as birr/ha.

- $\quad$ Total costs that vary (birr/ha) = sum of associated costs (in this case, it would be similar to the cost of seed).

- Net benefit (birr/ha) = Gross field benefits (birr/ha) - total costs that vary (birr/ha).

- $\quad$ Marginal profit $(\%)=$ Net benefit (birr/ha)/Total costs that vary $* 100$.

According to the economic analysis the validated tef varieties showed different results mainly Dega tef has the maximum net benefit $(79,536.69 \mathrm{birr} / \mathrm{ha})$ followed by Quncho $(67,106.97 \mathrm{birr} / \mathrm{ha})$ and Kora (63,746.96birr/ha). Variety Guduru has the least net benefit result of about $53,648.17 \mathrm{birr} / \mathrm{ha}$ which is by far lower than the local variety with net benefit of 61,757.38birr/ha. As the cost of local seed is much lower than the improved seed, marginal profit of the local variety is higher than the improved once. For instance, marginal profit of the second high yielder variety Quncho, is $\mathbf{2 3 9 6 . 6 7}$ is less than the local variety $\mathbf{4 1 1 7 . 1 5}$ (table 2). 
Fig 4: Net benefit and marginal profit of the varieties under evaluation

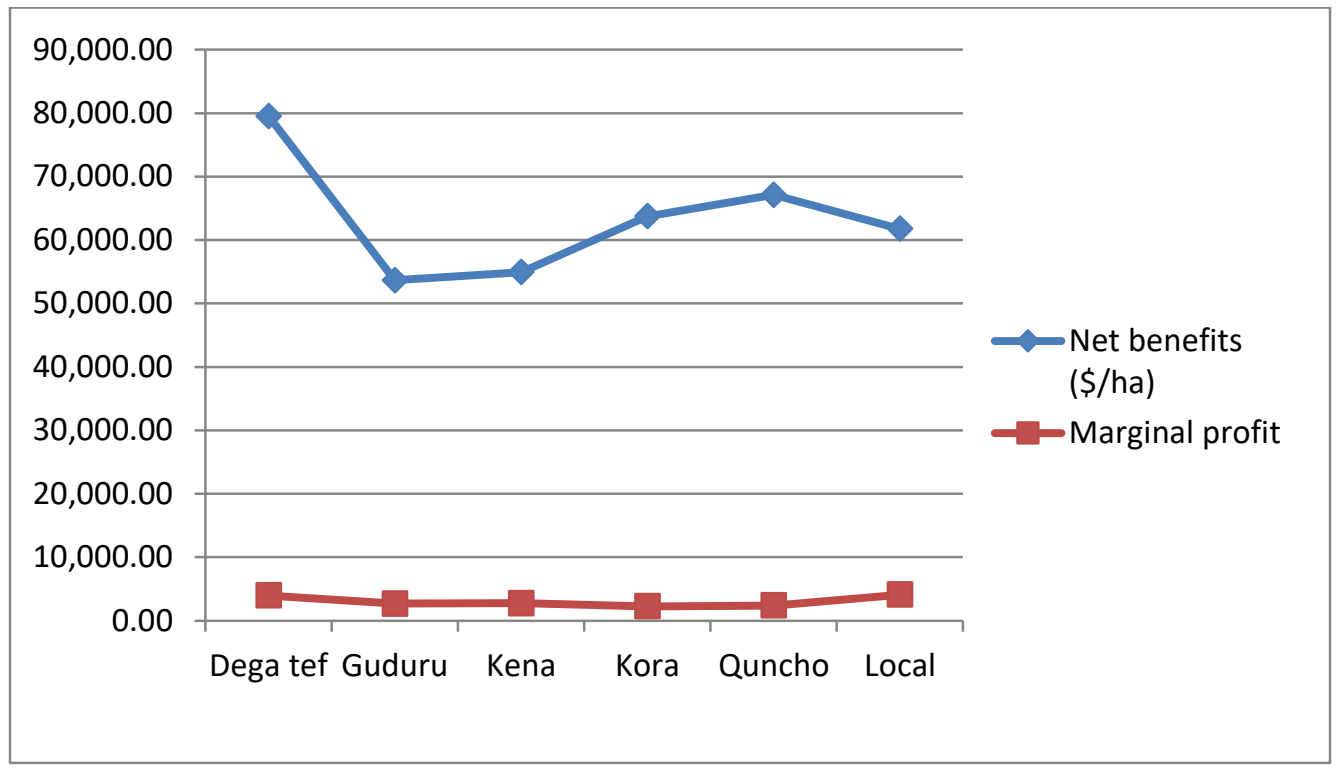

\section{Acceptability analysis}

Farmer's preference analysis system of CIAT (Guerrero et al., 1993) was employed for this validation activity. To identify the significance of their selection criterions A total of ten farmers were participated for participatory variety selection and they were asked to list a criterion that should be a standard for a given tef variety of their interest and they were supplemented by asking if the guiding questions listed are their point of interest or not. All the listed criteria were organized in to grain yield, biomass yield, tillering ability, and maturity time and market preference

In order to quantify the selected criteria's ratings were done by assigning numbers ( 1 =Excellent, $2=$ =very good, $3=$ good $4=$ poor, $5=$ very poor) for each varieties. They were told to give equal rate for the two or three varieties if they think it was equal for the traits in charge of comparison. The scores of preference ranking were treated as quantities measured on a continuous scale

Table 3: Acceptability score for tef varieties

\begin{tabular}{|c|c|c|c|c|c|c|c|c|c|c|c|c|c|c|}
\hline No & Varieties & F1 & F2 & F3 & F4 & F5 & F6 & F7 & F8 & F9 & F10 & Total & Prefe \% & Rank \\
\hline $\mathbf{1}$ & Dega tef & 21 & 21 & 25 & 19 & 21 & 22 & 26 & 22 & 25 & 23 & 225 & 75 & 1 \\
\hline $\mathbf{2}$ & Guduru & 6 & 6 & 7 & 6 & 6 & 7 & 7 & 6 & 7 & 6 & 64 & 21 & 6 \\
\hline $\mathbf{3}$ & Kena & 14 & 16 & 14 & 14 & 16 & 14 & 14 & 16 & 14 & 14 & 146 & 48 & 5 \\
\hline $\mathbf{4}$ & Kora & 19 & 25 & 19 & 21 & 24 & 22 & 18 & 25 & 18 & 19 & 210 & 70 & 3 \\
\hline $\mathbf{5}$ & Quncho & 24 & 25 & 24 & 22 & 25 & 22 & 21 & 14 & 22 & 21 & 221 & 73 & 2 \\
\hline $\mathbf{6}$ & Local & 24 & 12 & 18 & 18 & 13 & 18 & 15 & 12 & 18 & 21 & 169 & 56 & 4 \\
\hline
\end{tabular}

As the result from the farmer's preference analysis indicates that variety Dega tef was the first preferred variety followed by Quncho and Kora varieties based on its yield and yield related parameters. Varieties Guduru and kena were least in their performance and these varieties did not perform better on vertisol and hence farmers of the area were not interested on them. 
Fig 3: Acceptability score of the varieties under evaluation

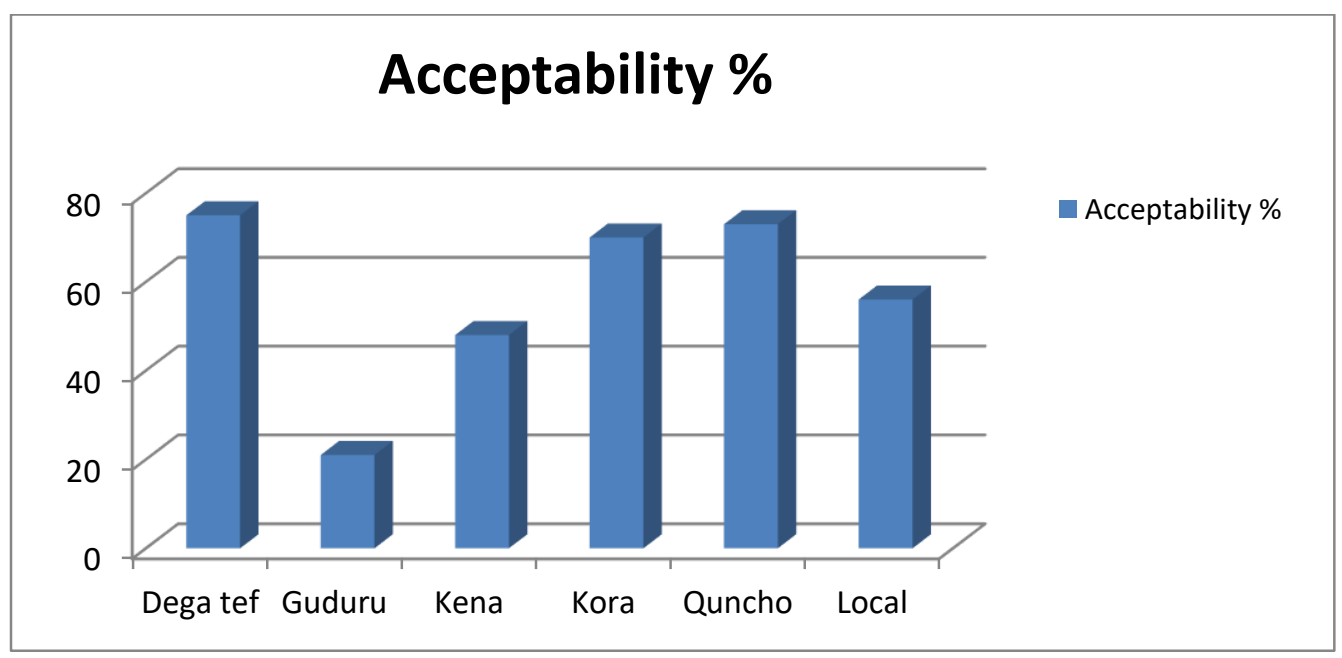

\section{Gender and Nutrition}

In most areas in rural Ethiopia, both male and female members of the farm household are involved in various types of farm activities. Newly introduced technologies and practices may require more family labor. It is known from literature and from different gender analysis reports that women face a heavy work burden, especially when the family does not have the means to hire daily laborers in the peak season. In our evaluation of improved tef varieties and production technologies the practice needs similar treatment in terms of gender especially in field cultivations such as field preparation, planting, weed management, harvesting and threshing. Therefore it is same as conventional practice in gender participation given the value of three in the protocol for the value of integrated technology validation.

\section{Environmental sustainability}

For environmental sustainability, two proxies- nutrient depletion rate and pesticide use are used. For this activity, no data was collected on nutrient depletion. However, the use of pesticides chemicals for the control of broad leaved weeds is the common practice for most of our farmers due to the difficulty of weed control by hand weeding as it needs more labor which majority of the farm house holds can't cover with their family labour. Pesticides have possible hazardous effects on acute and chronic toxicity for human, but also on a range of potential environmental effects such as pollinators, drinking water, non-target organisms. Even though we were tried to aware the use of Integrated Pest Management (IPM) approaches to manage the problem of pests, farmers participated in our field trial used 2-4, $\mathrm{D}$ for the control of broad leaved weeds and this herbicide chemical was grouped under class II of (WHO 2010) classification of hazardous chemicals which is given score of 1 in the set protocol and reduces the mean values of the varieties under evaluation. This implies how the evaluation activities were sensitive to environmental sustainability.

\section{Integration and Visualization of Results}

According to the protocol, the best performing varieties should be selected by integrating the aforementioned parameters. Therefore, integrating parameters and displaying the result into a single presentation panel i.e. spider graph is recommended. Hence, the results on 
productivity, profitability, acceptability, gender, nutrition and pesticide use have been normalized into a 1-5 scale and presented below (Table 4)

Table 4: Integrated scoring of technologies for tef validation trial

\begin{tabular}{|lcccccc|} 
& Dega tef & Guduru & Kena & Kora & Quncho & Local \\
\hline Productivity (tonnes/ha) & 5 & 4 & 4 & 5 & 5 & 5 \\
\hline Profitability (ETB/ha) & 5 & 3 & 3 & 4 & 4 & 3 \\
\hline Acceptability & 5 & 1 & 2 & 3 & 4 & 3 \\
\hline Gender /labour & 3 & 3 & 3 & 3 & 3 & 3 \\
\hline Nutrition (yes or no) & $\mathrm{N}$ & $\mathrm{N}$ & $\mathrm{N}$ & $\mathrm{N}$ & $\mathrm{N}$ & $\mathrm{N}$ \\
\hline Pesticide use & 1 & 1 & 1 & 1 & 1 & 1 \\
\hline Mean & $\mathbf{3 . 8}$ & $\mathbf{2 . 4}$ & $\mathbf{2 . 6}$ & $\mathbf{3 . 2}$ & $\mathbf{3 . 6}$ & $\mathbf{3 . 6}$ \\
\hline
\end{tabular}

Based on the rules of decision making and the integrated scoring for tef cultivars, three of the five improved varieties meet the requirements to be recommended. Therefore, Dega tef, Quncho and Kora were recommended for Becho areas and other areas with similar agroecological conditions in the central highlands of Ethiopia.

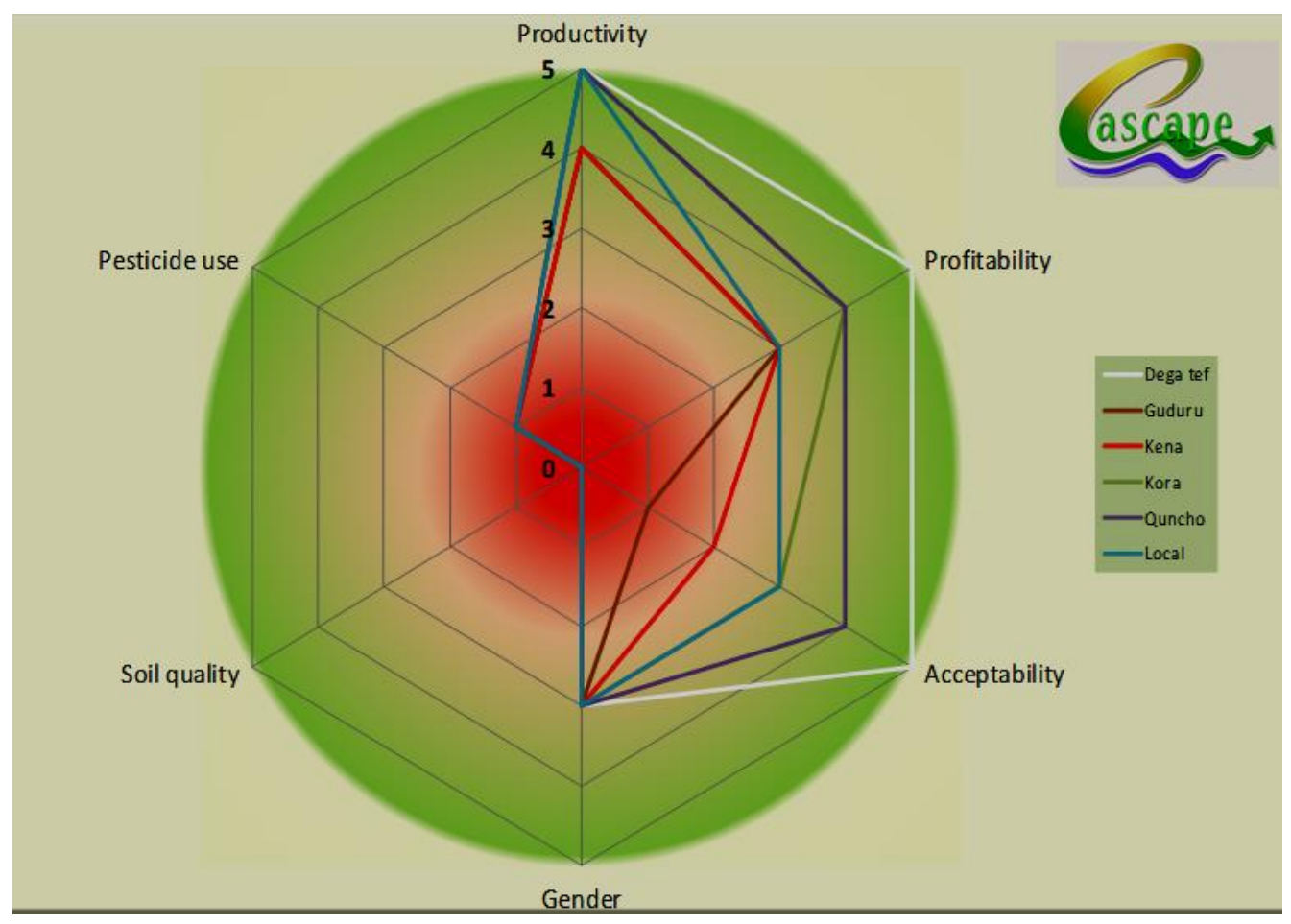

Fig 4: Spider diagram of integrated scoring of tef production technology validation

\section{Conclusion}

The long-sustained extensive cultivation of tef in Ethiopia can be attributed to its relative merits over other cereals both in husbandry and utilization. Of these, its merits in cultivation, include: (a) versatile adaptation 0 - $3000 \mathrm{~m}$ above sea level; (b) resilience to both 
drought and waterlogging stresses; (c) fitness for various cropping systems; (d) use as a catch and low-risk reliable crop especially in replacement cultures for failures of early sown long-season crops (e.g. maize and sorghum) due to environmental calamities or pests; and (e) little or no serious threats of disease and pest epidemics, at least, in its major production belts. On the other hand, its beneficial features with respect to utilization involve: (1) best quality and most consumer-preferred injera of the grains; (2) high returns in flour (Ebba 1969) and in injera; (3) minimal post-harvest losses due to storage pests and diseases coupled with high storage longevity (storability); (4) importance of the straw mainly as fodder for cattle and as a binder of mud used for plastering walls of local houses; and (5) cash crop value owing to the high market prices of both the grains and the straw.

Despite its popularity as a food crop, its productivity is very low (national average of about 1.6 tons/ha) mainly due to difficulties in its management and low genetic potential of local varieties as well as low adaptation of the improved varieties to different agro ecologies of the areas. Therefore, this study was mainly incited to evaluate the performance of the improved varieties of tef in central high lands which were released from the research systems of the country. Six tef varieties were tested for their performance evaluation to identify the best performing and superior variety in terms of yield, profitability, preference/acceptability, nutrition, gender and environmental sustainability parameters which were already set in the validation protocol.

According to the result of the study and the analysis of the set protocol from the evaluated tef varieties, Dega tef, Quncho and kora were identified as the pest performing varieties, so that these varieties were recommended for Becho areas and other areas with similar agroecological conditions in the central highlands of Ethiopia.

\section{ACKNOWLEDGEMENTS}

The authors gratefully acknowledge CASCAPE project for funding this research activity. The contribution of Becho district office of agriculture, experts and development agents in data collection and timely field supervision is highly acknowledged. The host farmers are highly appreciated for their collaboration and active participation in executing the experiment and we are deeply grateful to all of them and acknowledge their contribution.

\section{REFERENCES}

Alaunyte I., Stojceska V., Plunkett A., Ainsworth P., Derbyshire E. (2012). Improving the quality of nutrient-rich Teff (Eragrostis tef) breads by combination of enzymes in straight dough and sourdough breadmaking. J. Cereal Sci. 55 22-30 10.1016/j.jcs.2011.09.005

Assefa A. (2014). The dire need to support 'orphan crop' research [Online]. Sci Dev Net. Available at: http://www.scidev.net/global/agriculture/opinion/the-dire-need-to-support-orphan-cropresearch.html?hts0021=\&stay=full.

Central Statistical Authority (CSA), 2008: Statistical Abstract of Ethiopia 2008. Ethiopian agricultural research organization, Addis Ababa, Ethiopia.

CSA (Central Statistical Agency) (2017). Agricultural Sample Survey. Volume I: Report on Area and Production of Major Crops. Addis Ababa, Ethiopia.

Ebba, T., 1969: Tef (Eragrostis tef). The Cultivation, Usage and Some of Its Known Diseases and Insect Pests. Part I. Expt. Sta. Bull. No. 66. Haile Sellassie Univesity (HSIU), College of Agriculture, Dire Dawa, Ethiopia. 
Ketema S. (1997). Tef, Eragrostis tef (Zucc.) Trotter. Rome: Institute of Plant Genetics and Crop Plant Research, Gatersleben/International Plant Genetic Resources Institute.

Ketema, S., 1993: Tef (Eragrostis tef): Breeding, Genetic Resources, Agronomy, Utilization and Role in Ethiopian Agriculture. Institute of Agricultural Research, Addis Ababa, Ethiopia.

Naylor R. L., Falcon W. P., Goodman R. M., Jahn M. M., Sengooba T., Tefera H., et al. (2004). Biotechnology in the developing world: a case for increased investments in orphan crops. Food Policy 29 15-44 10.1016/j.foodpol.2004.01.002.

Spaenij-Dekking L., Kooy-Winkelaar Y., Koning F. (2005). The Ethiopian cereal tef in celiac disease. N. Engl. J. Med. 353 1748-1749 10.1056/NEJMc051492.

Spaenij-Dekking, L., Y. Kooy-Winkelaar, and F. Koning, 2005: The Ethiopian cereal tef in celiac disease. N. Engl. J. Med. 353, 16.

Tefera H, Belay G 2006: Eragrostis tef (Zuccagni) Trotter. [Internet] Record from Protabase. In:Brink M, Belay G(eds) PROTA (Plant Resources of Tropical Africa/Ressourcesvegetalesdel'Afriquetropicale),Wageningen.http://database.prota.org/search .htm (December, 2010).

Teklu Y, Tefera H 2005: Genetic improvement in grain yield potential and associated agronomic traits of tef (Eragrostis tef) Euphytica, 141, 247-254.

Vavilov, I., 1951: The Origin, Variation, Immunity and Breeding of Cultivated Plants. Translated from the Russian by K. S. Chester, Ronald Press Co, New York, USA. 
Gemechu and Besufekad: Evaluation of Improved Tef [Eragrostisteff /Zucc./Tratter] Production Technologies in Central High Lands of Ethiopia (IS-30) 